\title{
Integrating IT into teaching - struggling with windmills
}

\author{
Lilliam Hurst
}

Centre Informatique Pédagogique

Genève, Switzerland

\begin{abstract}
As soon as I started learning how to use the New Information Technology, I started trying to figure out ways to allow my students to enter the same marvellous world I was exploring. The windmills I had to struggle with were varied: the headmaster had to be convinced to fund the project ; my technology-resistant students had to be urged into the computer-room, then urged out again when they got hooked in turn; the colleagues had to be won over - this was a particularly resistant windmill. Much time was spent learning how to use the technology, acquiring new software, preparing menus to make the students' life easier, but that wasn't really a struggle. Other windmills reared up: the technical experts had to be convinced that having a language teacher in the "holy of holies" was not only a viable, but necessary; the librarian, who could have been another difficult windmill, turned out to be an ally. It was she who insisted that the computer should be in the library, as one tool among others. But windmills, if properly handled, can turn out to be allies in the end; and for the time being, they are providing me with energy.
\end{abstract}

Keywords: teaching methods, curriculum, communication, integration, motivation 


\section{INTRODUCTION}

"If I had the students 12 hours a week, I would try to integrate IT into my teaching" said one colleague. Her husband commented further: "My wife will not learn to use a computer because it's senseless to use something which is so complex - why, she would only ever be able to master about $5 \%$ of the entire process!" I haven't precisely observed her avoiding the use of her brain, however, and I have been told that we only use, at any given time, a tiny percentage of its capabilities...

I am a language teacher and my main professional purpose is and must remain language learning. I work at three sites in the State system of Canton Geneva - Collège Claparède, Collège pour Adultes and the Centre Informatique Pédagogique. In this paper I will address some of the issues I faced when starting to use computers for language learning. By tackling these issues, a wide range of curriculum related activities are now active on these sites.

\section{ENCOURAGING TEACHERS TO USE IT}

One of my aims as a teacher has been to become as contagious as possible, to persuade more and more of my colleagues to become involved in work with new information technology.

To do this, I have used the pebble-in-the pond approach. I started using Computer Assisted Language Learning (CALL) with my own students almost as soon as I had had been shown which button switched the machine on. My students were given instructions to enable them to use the programs I was installing on the hard disk of the computer in the library as fast as I could buy them. At first we used programs written by others, including exercises and feedback which were appropriate for our needs. Being eager to improve their English, however, my students swaggered into the library with their instruction-sheets, and at once became the envy of others, who borrowed the sheets, and started doing the work. This led to their asking their teachers why they weren't doing the same thing; teachers soon came to ask me to show them how. So the pebble made one circle of ripples - at least at my school.

Not everything went according to plan. The first windmill I had to struggle against was teacher indifference, not to say hostility. A first contact could be followed up by a suggestion that I be invited to a session 
with half-groups to show them what software was available, and how it worked. In many cases, the students were the motivators, which is an interesting reversal of the common situation.

The headmaster had to be convinced that, contrary to his original expectations, the extra time I was spending doing something which he hadn't initiated, had to be paid for. In a time of increasing budget restrictions, he had to make and keep a place in his budget for something which hadn't, until then, been high on his list of priorities and the utility of which he could only vaguely see. But, he worked on the principle: "If you can't lead, follow; and if you can't follow, then get out of the way".

At the beginning of each school year I have to convince my headmaster that he cannot afford not to have the new technologies in his budget for foreign language instruction. It takes a continuing effort to keep this weekly non-teaching hour in the budget, and in my contract. In return, I organise all the software for English, German and Italian, for my own use and for my language colleagues, who rely on this help. I would say that this is one of the hardest windmills that I have had to struggle with.

\section{Students' response}

Students have proved to be the most rewarding windmill to struggle with. Their responses have ranged from the unflattering: "I think it makes a change in the rhythm and it is a good way to teach us things that are boring to learn. It is also a chance for us to learn how a computer works. It's very useful" or "I think it's very good because we can work all the time (reference to the self-access system at Claparède), and it's very good for the future, because, actually, computers are very important in the world"; to an "allergic" student who declared that computers were not his "cup of tea", and that he wanted nothing to do with them.

I responded by continuing to give homework which was available only on the computer, and on which there was a test at the end of a certain period. This approach was more than vindicated by a visit from this 'allergic' student, during his second year with me. He wanted to know why I hadn't continued creating exercises for the fourth-year pupils - he had finished all of them, and it wasn't very pleasant to have to do exercises twice.

\section{Key relationships}

\section{Existing practice}

In our schools in Geneva, there is a technically oriented teacher, usually a teacher of computer science who is responsible for the upkeep and 
maintenance of the Local Area Network (LAN). That person can effectively keep other teachers, including language teachers, out of the computer lab, and a good relationship is essential with them if the projects are to succeed.

Relations with successive RAs

The first Responsable d'Atelier (RA) with whom I had to deal was Philippe Drompt, who was not only a computer genius, but was also convinced of the importance of language teachers for the future of the integration of the new technologies into the entire school curriculum. He provided key mentorship and help while I was myself learning about IT use. The current RA at our school is Derek White, who is unfailingly patient with requests for help. We feel that he is "on our side" and that is half the battle. Among other things, the computer department in my school finds it more convenient to have me attend all their meetings, so as to avoid having to transmit messages about what took place.

\section{Relations with the librarian}

The librarian was a key person for the installation of a stand-alone computer in the library, so that the students could see that it was simply one tool among many. Sadly, however, the stand-alone Mac was stolen from the library, and so removed from the students' reach.

\section{Relations with colleagues}

It seemed natural to share what I was learning with my colleagues. If it was making my life simpler, there was every reason in the world to allow them to have their lives simplified too.

When colleagues ask me how to use the new technologies, I first show them how the programmes work. Then, I hand out timetable sheets with my available hours so that they can issue official invitations to their half-group sessions. This means that when they have an hour slotted for smaller group-work, I go along and show the students what is available on the computer. It also allows me to tell the students that it is my work they will be destroying if they sabotage the programs, and to request their assistance in finding any mistakes I have made. It gives them a sense of responsibility and power to realize that they are being asked to work with me.

Colleagues from other schools have also asked me to show them our material. We usually have an after-school session at my school, so that they can explore the programmes; then I give them the menu-system I wrote so that they can start by doing the same thing. The data portion of our software, that is the exercises written by us, are of course available freely for others to use, with the request that they let us know if something 
can be improved upon. This has proven to be a problem at times, when colleagues call up at all hours and, without asking if the time is convenient, pitch right in with their comments, sometimes leaving me in the dark as to what they are talking about.

\section{Curriculum activities}

Below are some examples of a variety of curriculum examples that have been started, I have used these "success stories" in turn to attempt to make further ripples by providing examples of successful activities for colleagues to explore.

These activities involve use of the computer, but need not be exclusively limited to CALL. Many of these success stories have been collected and a monograph will be available by the time this paper goes to press.

Short story writing: using an activity taken from Ron White's Writing in Oxford Supplementary Skills [1], we have held simulation and incremental computer write-up sessions, leading to the completion of a 1000-word short story by the students.

Made-to-order exercises: we are constantly creating exercises that mesh with what we do in class, so that the students can reinforce and follow up work in class with sessions at the computer.

First Certificate request from pupils: the students who wish to do the First Certificate of English examination with the University of Cambridge Syndicate can do exercises taken from past exams, or prepare for the exam by using one of the few acceptable dedicated programmes in the field.

Diskette loans to adult students at Collège pour Adultes: until there is network access for all, I have instituted a disk lending system with my students at the Collège. They begin the year with student programs on disk-exercises relating to the first part of the curriculum; they return the disks to me around the middle of the year, and carry on with the second half of the curriculum also on disk. This is burdensome for me, as it involves a great deal of collating and copying, but it's better than nothing.

WDS disks to colleagues: my colleagues at the Collège pour Adultes have requested the vocabulary lists that we have typed in for the text books in use there. The student version of the program used for this has been shared with the colleagues requesting this. They in turn have found students who are computer literate enough to print out vocabulary lists for the entire class. 
$B B S$ "agony aunt" services: with one 3rd-year classics class, we have a local Bulletin Board Network group known as BENHURST. The students who belong to BENHURST have to send their Agony Aunt a message every ten days, with a query related to something we have been doing in class, or to a question that is still unclarified regarding English grammar, or, on any subject, as long as the question is in English. I then correct their English and answer their question. It is simply a modern version of the old classic Journal, whereby notebooks were filled with an on-going correspondence between teacher and learner. I have simply adapted this technique to the new technology. The success of this exchange has kept my mailbox filled to overflowing. The use of BENHURST has made available a cohort of sensitised students for work in 1992 described below.

\section{A communications network}

'Learning Circles' is a communication network consisting of 7 to 10 teams from different schools, constituted according to age, level, and interests of the pupils. On joining, the team can choose the area of the curriculum it wishes to work with. My school's choice was from:

- Journalism \& Language Arts (Computer Chronicles)

- Creative \& Expository Writing (Mind Works)

- History \& Geography (Places and Perspectives)

- Social Studies \& Current Issues (Global Issues)

- Social Studies (Society's Problems)

- Science \& Current Issues (Energy/Environment)

Messages are sent automatically to a central AT\&T computer by dedicated software which then redistributes them to the electronic 'mailbox' at each participating site. An interactive 'Learning Kit' helps the teacher to cope with the software, and on-line help is only a reverse-charge phone-call away. Within each circle, a volunteer Circle Co-ordinator serves as a role model, provides curriculum guidance and monitors Learning Circle progress.

Each class also chooses a 'project' to be more closely associated with, for example, sending out questionnaires with subsequent analysis or doing local research, with a report on the findings sent out to other members of the Circle. At the end of the session, each learning circle publishes a 'Circle Publication', under the aegis of the Co-ordinator.

Alongside the 'serious' work pertaining to their project, the students share personal experiences with their peers; this is one of their favourite times on the network, and several participating students carry on corresponding via 'real-mail' after the real session ends. 


\section{Social and political influences}

In 1992 a group of $17 / 18$ year-old students wanted in some way to make their mark in their network circle. Because there had been a scandal in Geneva, when the Council of State (the Chief Executive Body) had expelled a group of Albanians who were seeking political asylum, the students wanted to be able to discuss the event with some of the people involved in the decision. They therefore chose the theme Illegal Immigration.

Having chosen their theme, they composed a questionnaire - in French which then had to be translated into English. This was sent to our partners at the eight other schools of our Learning Circle, with the request that the questions be asked of anyone in power. Since most of the partner-schools were in areas far from the problems of illegal immigration, we did not receive any responses from them on this, but that was not viewed as a problem.

I wrote letters, on behalf of the students, to one right-wing politician in the Grand Conseil, the Legislative Branch of government, one moderate socialist, and, to round the picture out, to the President of the Department of Justice and Police, which had been the one most actively concerned by the expulsions. Those contacted all agreed to meet with the students, with the President of the J \& P Department sending them his Secretary General, due to lack of time.

In the event, the right-wing member of parliament, thrilled with what he saw as the opportunity to air his views, even offered to come to my class to explain to the students why the expulsion was not only necessary, but good, and in general why his party was the one they should adhere to. For various ethical reasons, we refused, but it was good for the students to realize that there was information to be garnered from the world outside school, and that they could not expect everything to automatically come to them.

Obtaining and translating the answers for our partners in the Learning Circle was a truly rewarding part of the activity. The students worked outside class time to do this and were very concerned that their written work should be checked so that it was a true reflection of what they had been told. I was being transformed into a facilitator - which I much preferred to the role of judge for the Learning Circle.

Once the questions had been asked (in French) and the answers faithfully jotted down, the students returned, and one student from each team of answer-gatherers became the head of another team of translators. The questions and answers had to be distributed to our partners in the Learning Circle. 


\section{CONCLUSION}

The pretext for doing all of this is the vehicular language, English. The main reason for our participating in any activity must, in my view, be subordinated to what is supposed to be my main goal - making my students independent and fluent in their use of English. It is fortunate that so many activities are available in this target language. The fact that most of the students in my school (and, I rather suspect, in many schools in non-anglophone countries) are eager to acquire competence in English simply makes the entire effort more feasible.

\section{REFERENCE}

1. White, R. (1987) Writing: Oxford Supplementary Skills, Oxford University Press.

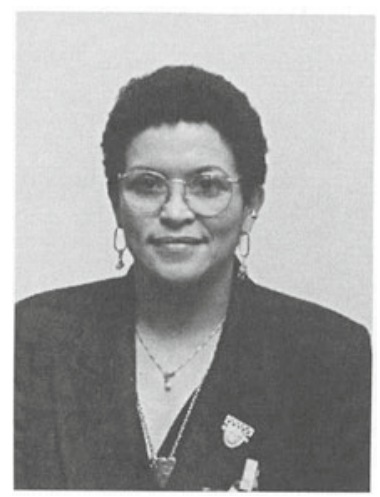

Lilliam Hurst moved to Switzerland in 1966 on a 'temporary' basis after obtaining her B.A. from a College in California and is still there.

She obtained a Licence ès Lettres from the University of Geneva in 1972, and has been teaching since 1976 (having obtained her Certification along the way). A British Council Specialist Course on CALL was the starting point for her interest in computer assisted learning and teaching, and her students' needs have drawn her ever further into the fascinating fields of self-access centres, telecomputing, and class-networking. 